University of Nebraska - Lincoln

DigitalCommons@University of Nebraska - Lincoln

Nebraska Extension Faculty \& Staff

Publications

Extension

$6-2010$

\title{
A comprehensive index for assessing environmental stress in animals
}

Terry L. Mader

Leslie J. Johnson

John B. Gaghan Dr

Follow this and additional works at: https://digitalcommons.unl.edu/extfacpub

Part of the Agricultural and Resource Economics Commons, Agricultural Education Commons, Food Science Commons, and the Rural Sociology Commons

This Article is brought to you for free and open access by the Extension at DigitalCommons@University of Nebraska - Lincoln. It has been accepted for inclusion in Nebraska Extension Faculty \& Staff Publications by an authorized administrator of DigitalCommons@University of Nebraska - Lincoln. 


\title{
A comprehensive index for assessing environmental stress in animals
}

\author{
Terry L. Mader, ${ }^{1}$ Leslie J. Johnson, ${ }^{1}$ and J. B. Gaughan ${ }^{2}$ \\ 1 University of Nebraska, Department of Animal Science, Concord, NE 68728 \\ 2 University of Queensland, School of Animal Studies, Gatton, Australia 4343 \\ Corresponding author — tmader@unlnotes.unl.edu
}

\begin{abstract}
Numerous models and indices exist that attempt to characterize the effect of environmental factors on the comfort of animals and humans. Heat and cold indices have been utilized to adjust ambient temperature (Ta) for the effects of relative humidity (RH) or wind speed (WS) or both for the purposes of obtaining a "feels-like" or apparent temperature. However, no model has been found that incorporates adjustments for RH, WS, and radiation (RAD) over conditions that encompass hot and cold environmental conditions. The objective of this study was to develop a comprehensive climate index (CCI) that has application under a wide range of environmental conditions and provides an adjustment to Ta for RH, WS, and RAD. Environmental data were compiled from 9 separate summer periods in which heat stress events occurred and from 6 different winter periods to develop and validate the CCI. The RH adjustment is derived from an exponential relationship between Ta and $\mathrm{RH}$ with temperature being adjusted up or down from an $\mathrm{RH}$ value of $30 \%$. At $45^{\circ} \mathrm{C}$, the temperature adjustment for increasing RH from 30 to $100 \%$ equals approximately $16^{\circ} \mathrm{C}$, whereas at $-30^{\circ} \mathrm{C}$ temperature adjustments due to increasing RH from 30 to $100 \%$ equal approximately $-3.0^{\circ} \mathrm{C}$, with greater RH values contributing to a reduced apparent temperature under cold

Published in Journal of Animal Science, volume 88, issue 6, June 2010, pages 2153-2165; and Journal of Animal Science, volume 89, issue 9, September 2011, page 2955 [Erratum]. doi:10.2527/jas.2009-2586 doi:10.2527/jas.2011-89-9-2955

Copyright (C) 2010 American Society of Animal Science; published by Oxford University Press. Used by permission. Submitted October 16, 2009; accepted January 29, 2010.

A contribution of the University of Nebraska, Agricultural Research Division, Lincoln.
\end{abstract}


conditions. The relationship between WS and temperature adjustments was also determined to be exponential with a logarithmic adjustment to define appropriate declines in apparent temperature as WS increases. With this index, slower WS results in the greatest change in apparent temperature per unit of WS regardless of whether hot or cold conditions exist. As WS increases, the change in apparent temperature per unit of WS becomes less. Based on existing windchill and heat indices, the effect of WS on apparent temperature is sufficiently similar to allow one equation to be utilized under hot and cold conditions. The RAD component was separated into direct solar radiation and ground surface radiation. Both of these were found to have a linear relationship with Ta. This index will be useful for further development of biological response functions, which are associated with energy exchange, and improving decision-making processes, which are weather-dependent. In addition, the defined thresholds can serve as management and environmental mitigation guidelines to protect and ensure animal comfort.

Keywords: bioclimatic index, cold stress, domestic livestock, environmental factor, environmental model, heat stress

\section{Introduction}

Limitations in air temperature alone, as a measure of the thermal environment, have resulted in efforts to produce an index which represents the net effect that environmental conditions may have on heat exchange processes (Hahn et al., 2003; Mader et al., 2006). Indices, which combine several environmental components, have been found to be very useful for characterizing environmental effects on animal productivity and wellbeing (Mader et al., 1997, 1999; Mader and Davis, 2004; Amundson et al., 2006). Historically, most efforts to develop thermal indices have been for human applications. For cold conditions, Siple and Passel (1945) developed a windchill index (WCI), relating ambient temperature (Ta) and wind speed (WS) to the time for freezing water. Recently, a new WCI equation has been developed that is biologically based and is now in use in Canada and the United States (Tew et al., 2002). Similarly, a new heat index (HI) has been developed to characterize the combined effects of Ta and percent relative humidity (RH) on humans (Rothfusz, 1990). For domestic animals, a comparable temperature-humidity index (THI) of Thom (1959) has been extensively applied for moderate to hot conditions (Hahn et al., 2003; Mader, 2003). Mader et al. (2006) developed adjustments to the THI based on panting scores and measures of WS and solar radiation (RAD). However, no index incorporates major environmental components that are experienced over a range of hot and 
cold conditions. In addition, appropriate environmental stress thresholds are needed that are flexible and can reflect stress levels based on environmental conditions, management levels, and physiological status. The objective of this research was to develop a comprehensive climate index (CCI) and comparable thresholds that utilize multiple environmental variables, incorporated into a continuous index that adjusts temperature for the combined effects of RH, WS, and RAD.

\section{Materials and methods}

All experiments reported herein, which were conducted at the University of Nebraska, were conducted with the approval of the University of Nebraska-Lincoln Institutional Animal Care and Use Committee.

The purpose of the CCI is to provide a relative indicator of the environmental conditions surrounding an animal. These desired mathematical relationships quantify how RAD, WS, and RH interact with Ta to produce an apparent temperature, which is represented by the CCI and adjusts Ta for the effects of respective environmental variables. Thus, equations were derived to allow adjustments to Ta due to the effects of RH, WS, and RAD. The equations developed by Mader et al. (2006) and Gaughan et al. (2008) served as foundation indices to describe the general relationship between respective environmental variables and Ta. The relationships were subsequently mathematically redefined based upon relationships observed among these same environmental variables, but when measured over a broader range of environmental conditions (NRC, 1981, 2000; Bourdon et al., 1984; Johnson, 1986). Initially, algorithms were developed that consisted of defining relationships between animal responses and environmental conditions, separately for hot and cold conditions. The final model was developed by combining these data sets to derive algorithms that can depict an apparent temper-

ature for the respective environmental variables under a wide range of environmental conditions.

\section{Model Development and Validation}

Data from previous models (Mader et al., 2006; Gaughan et al., 2008) were utilized to define the general relationship among Ta, RH, WS, and 
RAD for environmental conditions when Ta was above $5^{\circ} \mathrm{C}$. In those preliminary models, panting score was utilized as the primary animal response variable. For temperatures below $5^{\circ} \mathrm{C}$, the responses of animals to environmental variables were analyzed from studies reported by Birkelo and Lounsbery (1992), Stanton and Schutz (1996), Anderson and Schoonmaker (2005), Anderson et al. (2006), and Mader and Colgan (2007). Because there are few good physiological cold stress indicators and because DMI is driven by environmental conditions outside the thermal comfort zone (NRC 1981), DMI was utilized as the primary dependent variable to determine the relative effects of Ta, RH, WS, RAD, and WCI on the animal under cold conditions. From these studies, intermittent ( 14 to $84 \mathrm{~d}$ ) and overall ( $>84 \mathrm{~d}$ ) weigh period and daily environmental data were compiled. The relative effect of each independent variable on DMI was determined based on procedures outlined by Mader et al. (2006). Thus, adjustments to Ta and WCI were derived for RH and RAD. Separating Ta and WS did not improve accuracy of prediction. Thus, WCI was used as the basis for initial model development for $\mathrm{Ta}<5^{\circ} \mathrm{C}$. Because the WCI represents the apparent temperature when Ta is adjusted for WS, the general relationship between WS and Ta under cold conditions was already defined by WCI.

Once general relationships were defined among environmental variables, under separate hot and cold environmental conditions, generalized exponential and logarithmic algorithms were utilized to best describe relationships under a full range of environmental conditions that included the combined hot and cold data sets. In addition, because Ta is the primary indicator of comfort level, the model was developed to provide an index with numerical values that are in a physiological range and comparable with Ta.

The final model was based on environmental data compiled from weather stations located in areas in which heat waves had occurred over a 15-yr period. During the heat waves, livestock deaths were documented by state livestock association, state Department of Agriculture staff, USDA officials, or all 3 (Mader, 2003; Nienaber and Hahn, 2007). Reported losses were predominantly feedlot cattle maintained in outside facilities, although losses of other confined domestic livestock species were reported. Data from 7 of these events were utilized to aid in the CCI model development (Table 1). Similarly, data from 2 winters in which feedlot cattle performance and weather conditions were worse 
than normally expected were utilized to supplement the summer data. From this analysis, 3 general algorithms were developed to define the relationship between Ta and RH (Figure 1), Ta and WS (Figure 2), and Ta and RAD (Figure 3). In addition, based on analysis of data collected over a 7-yr period assessing the relationship between ground surface temperature and daily water intake (Arias, 2008; Arias and Mader, 2009), the RAD component was further subdivided; 1 equation was developed for direct solar radiation (DSR) and 1 equation was developed to depict the effects for radiation coming from the ground (STR). Because STR is a function of ground surface temperature, a separate equation was developed to depict the effects of STR based on ground surface temperatures. Thus, STR could be determined by RAD only or by ground surface temperature measures. The total effect of RAD is the combined effect of DSR plus STR.

Table 1. Hourly data from 7 heat stress events and 2 winters utilized for comprehensive climate index $(\mathrm{CCl})$ development

\begin{tabular}{|c|c|c|c|c|c|}
\hline Item & Mean & $S D$ & Minimum & Maximum & Range \\
\hline \multicolumn{6}{|l|}{ Summer conditions (45 d) } \\
\hline Ambient temperature $(\mathrm{Ta}),{ }^{\circ} \mathrm{C}$ & 23.52 & 5.46 & 9.15 & 37.15 & 7.87 to 42.54 \\
\hline Relative humidity (RH), \% & 73.01 & 18.03 & 28.62 & 99.00 & 7.87 to 100 \\
\hline Wind speed, $\mathrm{m} / \mathrm{s}$ & 3.48 & 1.67 & 0.77 & 9.32 & 0.45 to 12.15 \\
\hline Solar radiation, $\mathrm{W} / \mathrm{m}^{2}$ & 247.96 & 311.72 & 0.00 & 963.36 & 0 to $1,066.47$ \\
\hline $\mathrm{CCl},{ }^{\circ} \mathrm{C}$ & 24.23 & 7.56 & 5.69 & 44.48 & 2.62 to 47.86 \\
\hline Temperature-humidity index $(\mathrm{THI})^{2}$ & 71.01 & 7.04 & 48.66 & 86.24 & 46.30 to 88.12 \\
\hline Adjusted THI ${ }^{3}$ & 70.62 & 7.85 & 47.64 & 91.55 & 42.75 to 94.67 \\
\hline Heat index, ${ }^{4}{ }^{\circ} \mathrm{C}$ & 24.76 & 6.12 & 13.89 & 44.13 & 13.13 to 48.09 \\
\hline \multicolumn{6}{|l|}{ Winter conditions (Jan-Mar) } \\
\hline $\mathrm{Ta},{ }^{\circ} \mathrm{C}$ & -4.49 & 9.06 & -27.45 & 20.40 & -28.35 to 25.39 \\
\hline $\mathrm{RH}, \%$ & 82.79 & 13.23 & 25.35 & 100.00 & 22.80 to 100 \\
\hline Wind speed, m/s & 5.16 & 2.73 & 0.45 & 15.90 & 0.45 to 16.19 \\
\hline Solar radiation, $\mathrm{W} / \mathrm{m}^{2}$ & 118.04 & 189.77 & 0.00 & 805.65 & 0 to 813.15 \\
\hline $\mathrm{CCl},{ }^{\circ} \mathrm{C}$ & -13.58 & 11.10 & -39.61 & 19.88 & -39.67 to 25.54 \\
\hline Wind chill index,$^{5} \mathrm{C}$ & -10.19 & 11.30 & -38.28 & 21.04 & -38.69 to 26.79 \\
\hline
\end{tabular}

1 From Ta + Eq. [1] $+[2]+[3]$.

$2 \mathrm{THI}=(0.8 \times \mathrm{Ta})+[(\mathrm{RH} / 100) \times(\mathrm{Ta}-14.3)]+46.4$.

3 From Mader et al. (2006).

4 From Rothfusz (1990).

5 From Tew et al. (2002). 


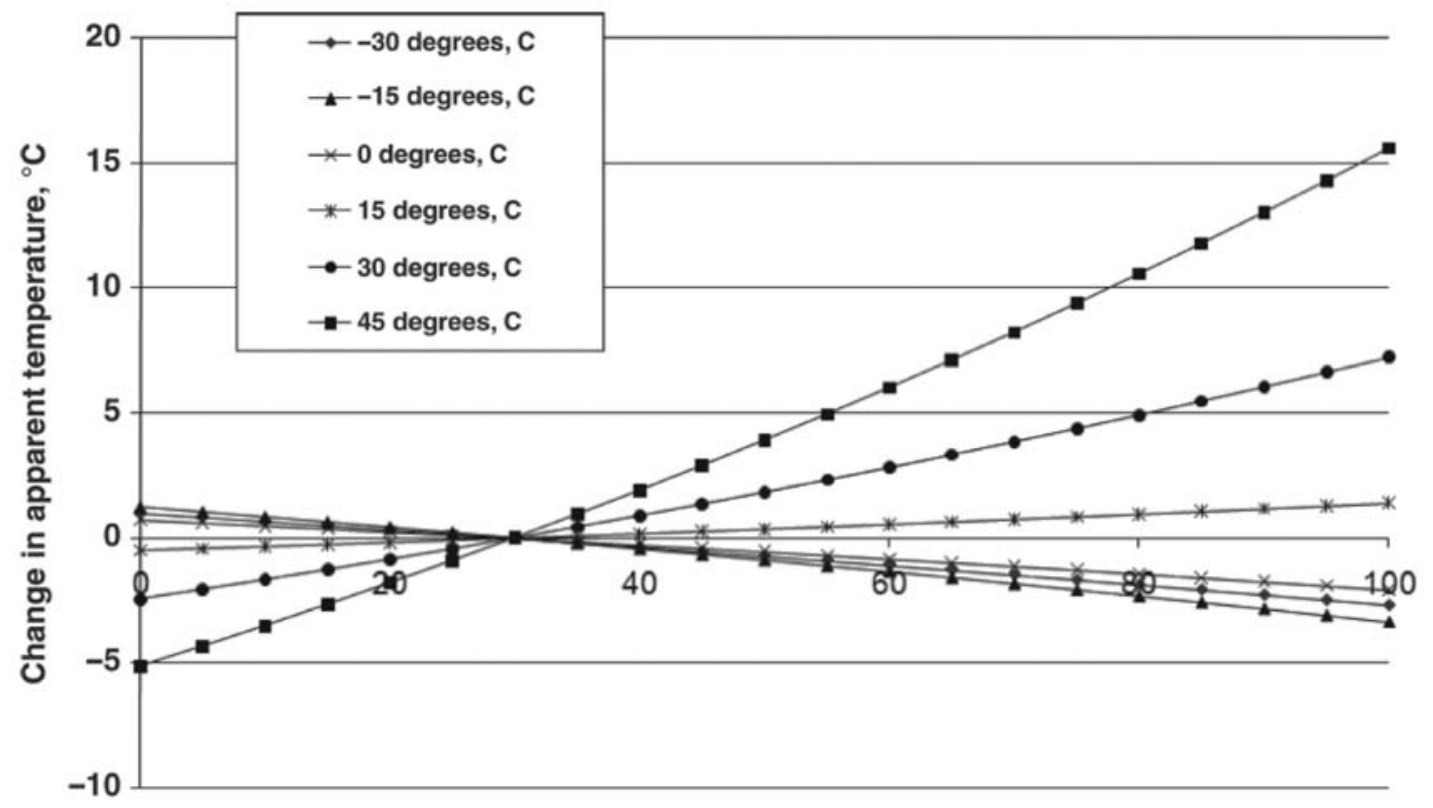

Relative humidity, \%

Figure 1. Temperature adjustments for the comprehensive climate index, based on percent relative humidity at different ambient temperatures.

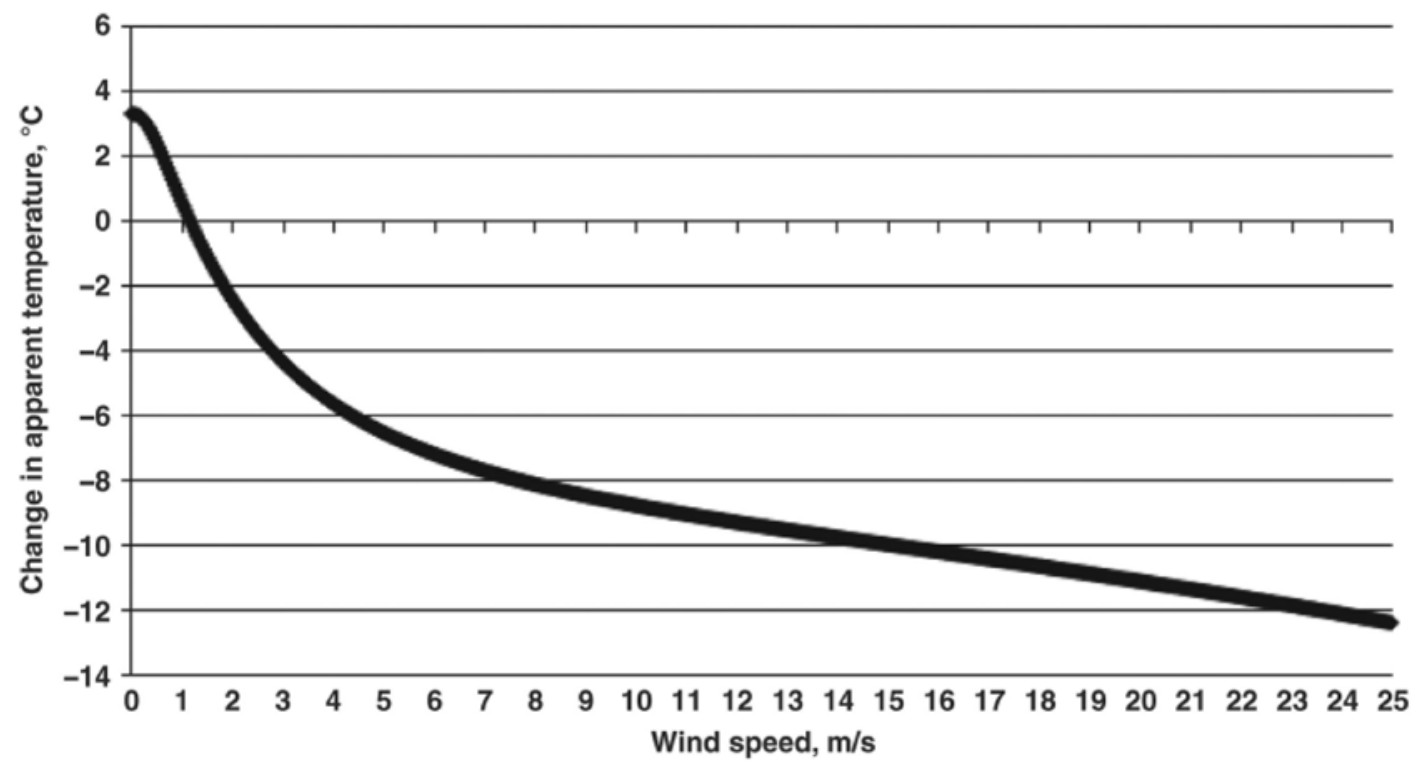

Figure 2. Temperature adjustments for the comprehensive climate index based on wind speed. 


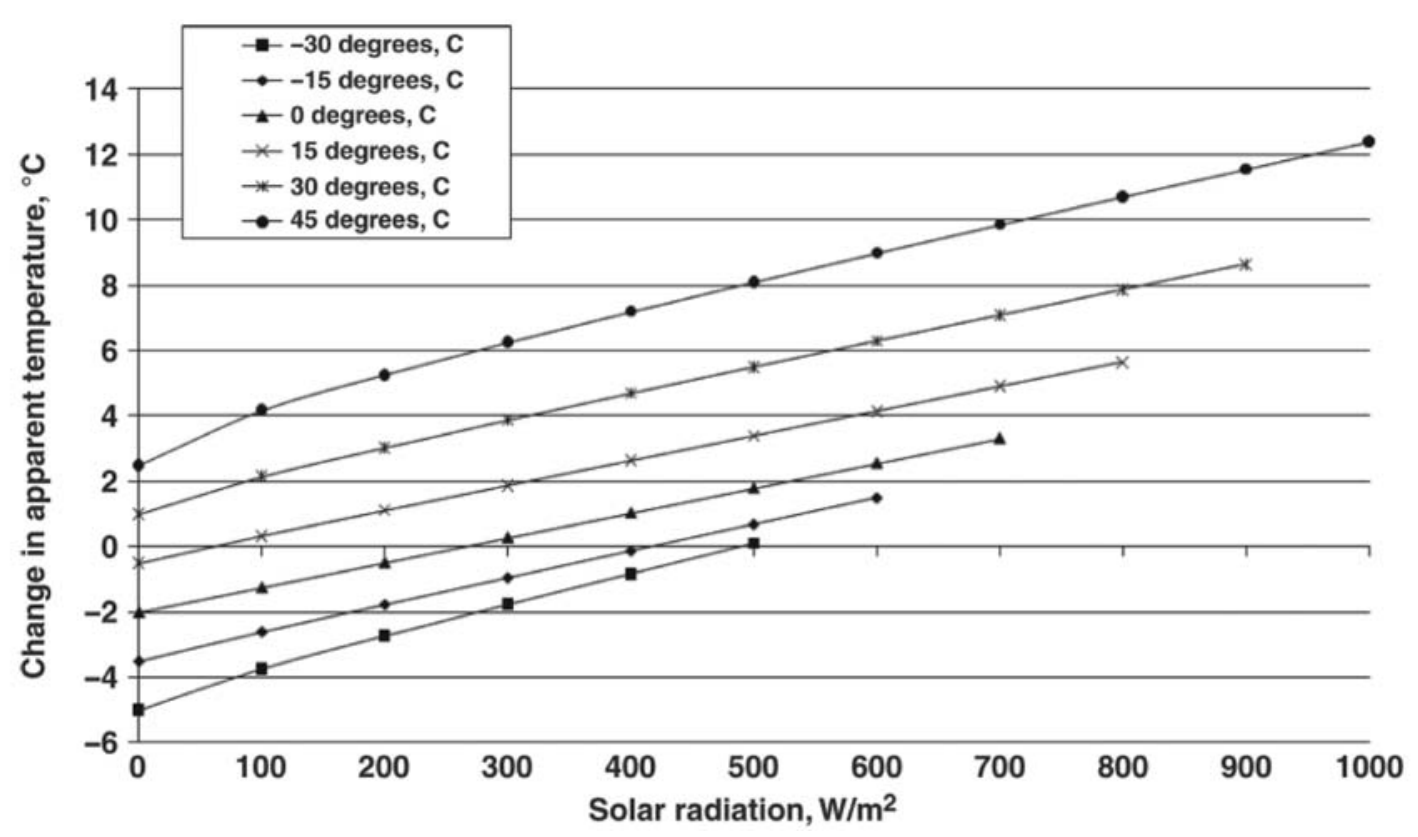

Figure 3. Temperature adjustments for the comprehensive climate index based on solar radiation at different ambient temperatures.

Model validation (Table 2) was based on conditions associated with 2 summers (2007 and 2009) in which livestock deaths occurred as a result of heat stress (Brown-Brandl et al., 2008; Cattle Network, 2009). Within each year, environmental data were obtained and compared from locations in which 1) limited livestock losses were reported, 2) livestock losses up to $2 \%$ were reported, and 3 ) livestock losses in excess of $5 \%$ were reported in some operations. To assess the validity of the CCI under winter conditions, environmental data were also obtained from 4 winter periods ( 2 typical winters and 2 winters in which temperatures were below normal). Also, because DMI was utilized to derive some animal response relationships to environmental variables, data from Kreikemeier and Mader (2004) were utilized to assess the relationship between the CCI and DMI over summer and winter conditions, in which cattle of similar sex, age, BW, body condition, and breed composition were utilized each season.

To further validate the CCI, values were compared with the THI and adjusted THI (Mader et al., 2006) and both the WCI and HI. Based on numerical agreements with those indices, physiologically realistic thresholds were defined which characterize the discomfort levels that are 
Table 2. Comparison of the comprehensive climate index $(\mathrm{CCl})$ to the temperaturehumidity index (THI), adjusted THI, heat index, and wind chill index during adverse environmental conditions 1

\begin{tabular}{|c|c|c|c|c|c|}
\hline Item & Mean & $S D$ & Minimum & Maximum & Range \\
\hline \multicolumn{6}{|l|}{ Summer conditions $(2 \mathrm{~d})$} \\
\hline \multicolumn{6}{|c|}{ Limited livestock deaths reported } \\
\hline Ambient temperature $(\mathrm{Ta}){ }^{\circ} \mathrm{C}$ & 25.84 & 3.95 & 19.55 & 32.32 & 19.22 to 33.84 \\
\hline Relative humidity $(\mathrm{RH}), \%$ & 80.58 & 13.58 & 53.11 & 98.85 & 36.76 to 99.70 \\
\hline Wind speed, $\mathrm{m} / \mathrm{s}$ & 3.03 & 1.20 & 1.48 & 5.67 & 1.26 to 5.73 \\
\hline Solar radiation, $\mathrm{W} / \mathrm{m}^{2}$ & 284.44 & 334.07 & 0.00 & 900.66 & 0 to 931.17 \\
\hline $\mathrm{CCl}^{2}{ }^{\circ} \mathrm{C}$ & 28.47 & 6.49 & 17.70 & 41.06 & 16.52 to 43.47 \\
\hline $\mathrm{THI}^{3}$ & 75.77 & 4.93 & 67.07 & 82.63 & 66.50 to 82.84 \\
\hline Adjusted $\mathrm{THI}^{4}$ & 76.18 & 6.41 & 64.58 & 87.75 & 62.64 to 88.74 \\
\hline Heat index,$^{\circ} \mathrm{C}$ & 26.78 & 6.80 & 15.23 & 37.07 & 15.13 to 37.54 \\
\hline \multicolumn{6}{|c|}{ Livestock losses of 1 to $2 \%$ above average } \\
\hline $\mathrm{Ta}^{\circ}{ }^{\circ} \mathrm{C}$ & 27.07 & 4.33 & 20.44 & 34.68 & 19.74 to 36.36 \\
\hline $\mathrm{RH}, \%$ & 78.68 & 14.94 & 46.22 & 97.80 & 37 to 100 \\
\hline Wind speed, m/s & 2.69 & 1.20 & 0.57 & 5.69 & 0.45 to 6.86 \\
\hline Solar radiation, $\mathrm{W} / \mathrm{m}^{2}$ & 267.69 & 325.42 & 0.00 & 884.16 & 0 to 947.17 \\
\hline $\mathrm{CCl},{ }^{\circ} \mathrm{C}$ & 30.55 & 6.43 & 19.53 & 43.43 & 16.73 to 45.48 \\
\hline $\mathrm{THI}^{3}$ & 77.52 & 5.19 & 68.53 & 85.13 & 67.01 to 87.78 \\
\hline Adjusted THI ${ }^{4}$ & 78.49 & 6.46 & 65.51 & 90.87 & 60.43 to 92.98 \\
\hline Heat index,$^{\circ} \mathrm{C}$ & 29.58 & 7.74 & 17.39 & 41.77 & 16.69 to 46.78 \\
\hline \multicolumn{6}{|c|}{ Livestock losses in some operations exceeding $5 \%$} \\
\hline $\mathrm{Ta},{ }^{\circ} \mathrm{C}$ & 28.52 & 4.22 & 22.82 & 35.72 & 22.62 to 36.30 \\
\hline $\mathrm{RH}, \%$ & 69.78 & 15.97 & 40.19 & 92.15 & 34.36 to 96.60 \\
\hline Wind speed, $\mathrm{m} / \mathrm{s}$ & 2.47 & 1.30 & 0.59 & 5.48 & 0.45 to 7.30 \\
\hline Solar radiation, $\mathrm{W} / \mathrm{m}^{2}$ & 340.34 & 381.66 & 0.00 & 988.74 & 0 to $1,115.32$ \\
\hline $\mathrm{CCl}^{2}{ }^{\circ} \mathrm{C}$ & 32.86 & 6.72 & 22.89 & 44.59 & 20.05 to 45.42 \\
\hline $\mathrm{THI}^{3}$ & 78.45 & 4.12 & 71.76 & 84.38 & 71.42 to 84.54 \\
\hline Adjusted THI ${ }^{4}$ & 80.34 & 6.56 & 69.25 & 91.04 & 64.66 to 91.63 \\
\hline Heat index, $5^{\circ} \mathrm{C}$ & 30.75 & 6.11 & 21.97 & 39.83 & 21.63 to 40.09 \\
\hline \multicolumn{6}{|l|}{ Winter conditions (10 d) } \\
\hline \multicolumn{6}{|l|}{ Desirable years } \\
\hline $\mathrm{Ta},{ }^{\circ} \mathrm{C}$ & -9.73 & 4.13 & -18.47 & 0.27 & -19.27 to 0.88 \\
\hline $\mathrm{RH}, \%$ & 80.84 & 9.52 & 50.90 & 94.30 & 48.99 to 95.60 \\
\hline Wind speed, $\mathrm{m} / \mathrm{s}$ & 4.33 & 1.76 & 1.17 & 9.85 & 1.147 to 10.54 \\
\hline Solar radiation, $\mathrm{W} / \mathrm{m}^{2}$ & 73.06 & 121.19 & 0.00 & 440.93 & 0 to 475.99 \\
\hline $\mathrm{CCl}^{2}{ }^{\circ} \mathrm{C}$ & -19.68 & 4.75 & -28.31 & -7.80 & -30.33 to -6.79 \\
\hline Wind chill index, ${ }^{6}{ }^{\circ} \mathrm{C}$ & -16.16 & 4.58 & -25.04 & -4.99 & -26.7343 to -4.47 \\
\hline \multicolumn{6}{|l|}{ Undesirable years } \\
\hline $\mathrm{Ta},{ }^{\circ} \mathrm{C}$ & -16.35 & 5.75 & -27.16 & 0.41 & -27.33 to 2.40 \\
\hline $\mathrm{RH}, \%$ & 78.13 & 8.32 & 54.79 & 93.95 & 49.87 to 95.70 \\
\hline Wind speed, $\mathrm{m} / \mathrm{s}$ & 6.54 & 3.56 & 0.80 & 14.49 & 0.66 to 15.46 \\
\hline Solar radiation, $\mathrm{W} / \mathrm{m}^{2}$ & 69.91 & 114.70 & 0.00 & 403.02 & 0 to 421.98 \\
\hline $\mathrm{CCl}_{1}^{2}{ }^{\circ} \mathrm{C}$ & -28.06 & 6.84 & -41.03 & -7.81 & -43.54 to -3.76 \\
\hline Wind chill index, ${ }^{6}{ }^{\circ} \mathrm{C}$ & -25.92 & 7.90 & -41.04 & -5.31 & -45.51 to -1.73 \\
\hline
\end{tabular}

\footnotetext{
1 Hourly data derived from 3 locations for each of 2 heat stress events, which occurred in separate years, and from the coldest portions of 2 desirable winters and 2 undesirable winters for feeding livestock outdoors.
}

2 From Ta + Eq. [1] $+[2]+[3]$.

$3 \mathrm{THI}=(0.8 \times \mathrm{Ta})+[(\mathrm{RH} / 100) \times(\mathrm{Ta}-14.3)]+46.4$.

4 From Mader et al. (2006).

5 From Rothfusz (1990).

6 From Tew et al. (2002). 
experienced by animals as well as humans. These thresholds were developed based on comparative thresholds associated with other models, environmental conditions, or both that are known to be adverse to livestock (LCI, 1970; NRC, 1981; Stanier et al., 1984; Johnson, 1994; NOAA, 2009).

Hourly environmental data were obtained from the Automated Weather Data Network of the High Plains Regional Climate Center (HPRCC) or from similar weather stations maintained by HPRCC technicians. All winter environmental data were obtained from weather stations at the feedlot site or from the HPRCC weather station listed for the town address of the feedlot site. All summer environmental data were obtained from weather stations within the county or generalized area livestock deaths were reported. Ground surface temperature data were obtained for 2 heat stress events for development and model validation and also for 2 sets of winter data for model development and validation. Ground surface temperatures were obtained using a Model 4000 Infrared Transducer (Everest Interscience Inc., Tucson, AZ) linked to the weather station data loggers. Details of these weather stations are provided by Hubbard et al. (1983).

\section{Statistical Analysis}

Modeling techniques outlined by Mader et al. (2006) and Gaughan et al. (2008) were employed for index and threshold development. Initial model components were developed by using various regression analyses (SAS Inst. Inc., Cary, NC). Additional model components were further refined using PROC CORR, PROC MIXED, and PROC GLM options of SAS. Excel 2007 (Microsoft Corp., Redmond, WA) was utilized for simple analysis and plotting of model component combinations during the model development and validation process.

For each environmental variable, the specific adjustment to Ta was defined by linear and polynomial relationships under respective hot and cold conditions. The relative rate of change, or adjustment to Ta for each environmental variable, was defined as the ratio of the coefficient of the respective variable to the Ta coefficient as described by Mader et al. (2006). Coefficients were derived from the relationship between the various environmental variables and the animal response via regression analysis. 
Once these relationships were defined, hot and cold data sets were subsequently combined within an environmental variable; data points were then fit to a mathematical model that best described the relationship between Ta and the environmental variable being evaluated over a full range of temperatures. Polynomial, exponential, logarithmic, and respective inverse mathematical models were evaluated for each environmental variable.

Submodels were derived for each environmental variable. Within respective submodel algorithms, coefficients and combinations of coefficients were derived. The final combination of coefficients utilized were based on and determined by the best fit $\left(\mathrm{R}^{2}\right)$ when compared with previously defined indices or relationships that were defined in the initial analysis in which the hot and cold components were defined separately or both. The final CCI is a combination of submodels. The CCI and associated submodels were validated by comparing the CCI to known indices (THI, HI, and WCI) using regression analysis.

\section{Results}

The CCI was developed under environmental conditions associated with Ta from approximately -30 to $45^{\circ} \mathrm{C}$ and provides an adjustment to Ta for RH (Eq. [1]), WS (Eq. [2]), and RAD (Eq. [3]). The CCI or apparent temperature is defined as Ta + Eq. [1] + Eq. [2] + Eq. [3].

\section{RH correction factor}

\section{Equation [1]}

$$
\begin{aligned}
= & e^{\left(0.00182 \times R H+1.8 \times 10^{-5} \times T a \times R H\right)} \\
& \times\left(0.000054 \times T a^{2}+0.00192 \times T a-0.0246\right) \times(R H-30)
\end{aligned}
$$

\section{WS correction factor}

\section{Equation [2]}

$$
=\left[\frac{-6.56}{\left.e^{\left\{\left\langle 1 /(2.26 \times \mathrm{WS}+0.23)^{0.45}\right\rangle \times\left\langle 2.9+1.14 \times 10^{-6} \times \mathrm{WS}^{2.5}-\log _{0.3}(2.26 \times \mathrm{WS}+0.33)^{-2}\right)\right\}}\right]}\right.
$$




\section{RAD correction factor}

\section{Equation [3]}

$$
\begin{aligned}
= & 0.0076 \times R A D-0.00002 \times R A D \times T a \\
& +0.00005 \times T a^{2} \times \sqrt{ } R A D+0.1 \times T a-2
\end{aligned}
$$

Graphical representations of these equations and predicted outcomes are shown in Figures 1, 2, and 3, respectively. Unlike the THI and HI, the $\mathrm{RH}$ adjustment is derived from an exponential relationship between temperature and RH with temperature being adjusted up and down from RH values that are above and below $30 \% \mathrm{RH}$ (Eq. [1]). At $45^{\circ} \mathrm{C}$, the temperature adjustment for increasing RH from 30 to $100 \%$ equals approximately $16^{\circ} \mathrm{C}$, whereas at $-30^{\circ} \mathrm{C}$, the temperature adjustments due to increasing $\mathrm{RH}$ from 30 to $100 \%$ is approximately $-3.0^{\circ} \mathrm{C}$, with greater $\mathrm{RH}$ values contributing to a reduced apparent temperature under cold conditions (Figure 1). For RH above $30 \%$ and Ta less than $5^{\circ} \mathrm{C}$, there is a downward or negative adjustment in Ta. This is attributed to the greater RH diminishing or limiting hide and hair coat drying or both, contributing to cold stress. This effect is greatest between 0 and $-15^{\circ} \mathrm{C}$, when precipitation is in a form that contributes or has a high probability of contributing to wet animal and ground surface conditions. As Ta drops below $-15^{\circ} \mathrm{C}$, the negative effect of $\mathrm{RH}$ is lessened.

The relationship between WS and temperature adjustments was also determined to be exponential with a logarithmic adjustment to define appropriate declines in apparent temperature as WS increases (Figure 2). With this index, slow WS results in the greatest change in apparent temperature per unit of WS regardless of whether hot or cold conditions exist. As WS increases, the change in apparent temperature per unit of WS becomes less. Based on the WCI and algorithms developed by Gaughan et al. (2008), the effect of WS on apparent temperature was found to be similar enough to allow 1 equation to be utilized under hot and cold conditions.

The effects of RAD on temperature change are shown in Figure 3. At subfreezing temperatures the efficiency at which a biological entity utilizes RAD differs from that under hot conditions, due to body orientation, surface contact, and so on; thus adjustments to temperature for RAD are slightly greater per unit of radiation under the coldest conditions (Keren and Olson, 2006). However, the total adjustment will be much less under cold conditions due to the limited amount of RAD provided (e.g., winter conditions). 
An example CCI calculation for environmental conditions, represented by Ta, RH, WS, and RAD of $30^{\circ} \mathrm{C}, 50 \%, 1.0 \mathrm{~m} / \mathrm{s}$, and $500 \mathrm{~W} / \mathrm{m}^{2}$, respectively, would be as follows: $30^{\circ} \mathrm{C}+1.8$ (RH adjustment from Eq. [1]) +0.6 (WS adjustment from Eq. [2]) + 5.5 (RAD adjustment from Eq. [3] = 37.9.

Even though the model is designed so that only the Ta and RAD component is needed to calculate the Ta adjustment, the RAD component Eq. [3] can be separated into the effects of DSR (Eq. [3a]) and effects of surface temperature as derived from RAD (STR; Eq. [3b]). Under hot conditions, radiant heat from the ground contributes to the heat load of the animal in addition to the DSR, whereas under cold conditions heat is transferred from the body to the ground. Furthermore, Arias and Mader (2009) demonstrated that ground surface temperatures have a significant impact on the animal and a positive relationship $\left(\mathrm{R}^{2}=0.70\right.$ to 0.86$)$ to water intake. Thus, the STR adjustment for ground surface radiant effects to Ta would be determined by using Eq. [3c] instead of Eq. [3b]. Therefore, if ground surface temperature is known, the RAD adjustment equals Eq. [3a] + Eq. [3c]. The relationship between temperature adjustment based on surface temperature (Eq. [3c]) and solar radiation (Eq. $[3 \mathrm{~b}])$ is shown in Figure $4\left(\mathrm{R}^{2}=0.98\right)$. Based on the previous example calculation, the DSR contribution would be 3.55 (from Eq. [3a]) and the STR would be 1.95 (from Eq. [3b]). The approximate surface temperature would be $39.5^{\circ} \mathrm{C}$. The STR calculation would be 1.95 (from Eq. [3c]) or equivalent to that found for Eq. [3b]. Where surface temperature measures are not obtainable, the default adjustment to the surface radiation equation was derived from Ta and RAD as shown in Eq. [3b]. Under those conditions, the adjustment for total radiation is associated with Ta and RAD readings only, which is fully expressed in Eq. [3], which is Eq. [3a] plus Eq. [3b].

[3a] Direct solar radiation correction factor

$$
\begin{aligned}
& =0.0057 \times R A D-0.00002 \times R A D \times T a \\
& +0.00005 \times T a^{2} \times \sqrt{R A D}
\end{aligned}
$$

[3b] Surface temperature correction factor

$$
=0.1 \times(T a+0.019 \times R A D)-2
$$

[3c] Surface temperature correction factor

$$
=0.1 \times(\text { surface temperature })-2
$$




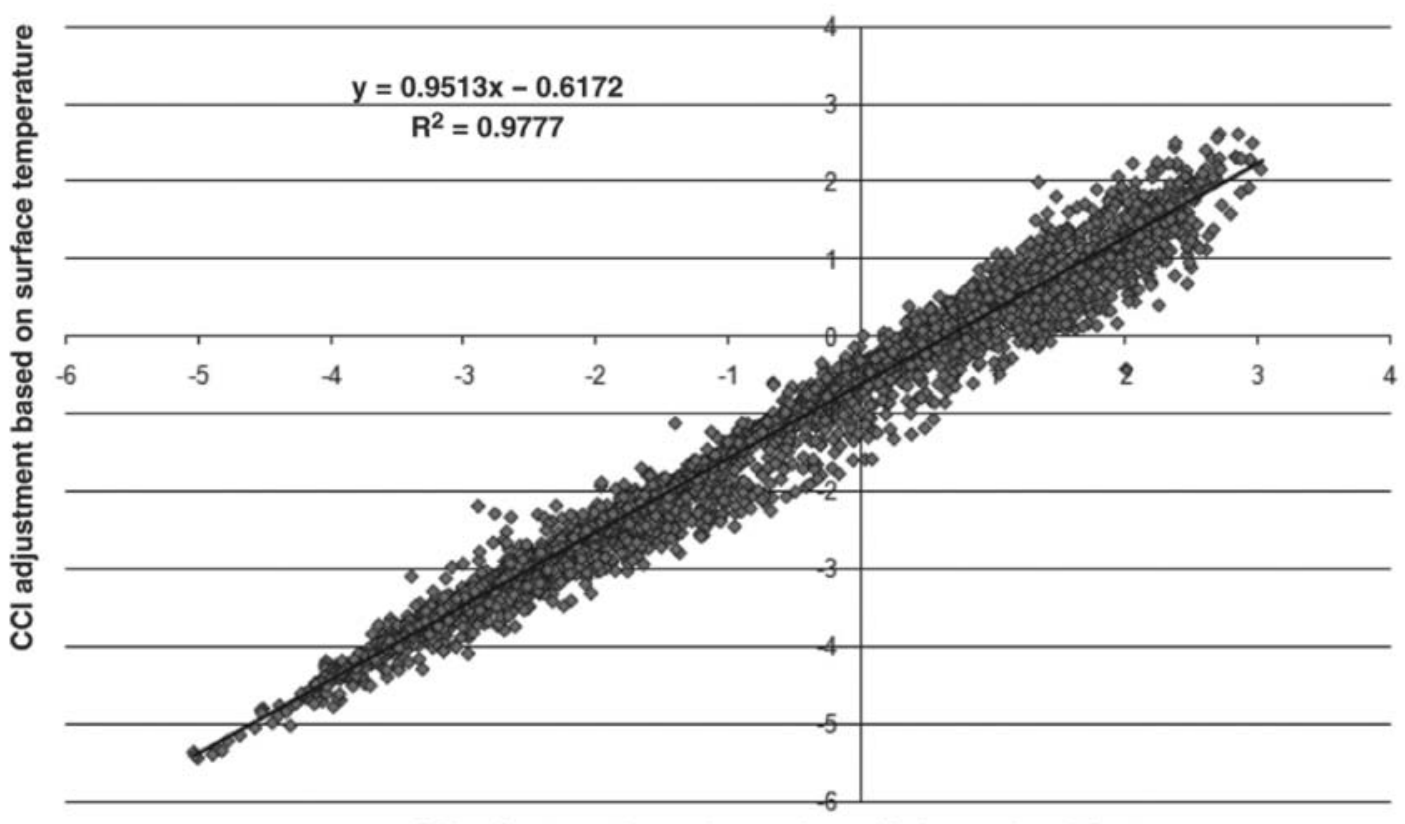

$\mathrm{CCl}$ adjustment based on solar radiation and ambient temperature

Figure 4. Relationship between temperature for ground surface temperature adjustment to the comprehensive climate index (CCI) based on actual ground surface temperature measures and ground surface adjustment based on solar radiation and ambient temperature measures.

Calculating the RAD component by using Eq. [3a] plus [3c] vs. Eq. [3] allows adjustments to be made for animals exposed to ground or floor surfaces, which differ in radiant heat-generating capacity. The STR correction will generally be between -5 and $3^{\circ} \mathrm{C}$ (Figure 4), whereas total RAD correction will range from -5 to over $10^{\circ} \mathrm{C}$ (Figure 3). Thus, the STR correction will constitute a greater portion of the overall RAD correction under cold conditions (being negative) but a proportionally smaller portion of the RAD correction under hot conditions. Under hot conditions, DSR adjustment will exceed the STR adjustment, which is in agreement with Bond et al. (1967) and Kelly and Bond (1971) who reported that emitted radiant energy from the ground can contribute to over $300 \mathrm{~W} /$ $\mathrm{m}^{2}$ of emitted radiation being received by a standing animal. Although the adjustment is small, if needed, an additional adjustment for different surface solar radiation absorbencies and emissitivities can be incorporated into correction based on surface type and environmental conditions (Kelly and Bond, 1971). 
Additional algorithms (not shown) were developed to account for the differential heat transfer that occurs at different Ta but with the same WS. The algorithm accounted for the potential heat gain due to wind when Ta is greater than body temperature. Also, the algorithm was designed to account for body heat transfer that is associated with evaporative and radiative processes or radiative processes only. However, the use of this algorithm did not significantly improve the applicability or functionality of the model and, therefore, was not included in the final product. In addition, the effects of WS at a given temperature may vary with $\mathrm{RH}$, especially under conditions in which animals use evaporative cooling processes to regulate body temperature. Because 3 previous models (Eigenberg et al., 2005; Mader et al., 2006; Gaughan et al., 2008) failed to detect or report or both this effect, no submodel or algorithms were developed to define this phenomena.

The relationship between daily DMI and CCI is shown in Figure 5. Generally, relationships between environmental variables and DMI tend to be weak ( $\mathrm{R}^{2}$ between 0 and 0.50$)$. By combining all environmental variables, $\mathrm{R}^{2}$ of 0.70 (linear) and 0.71 (quadratic) were able to be obtained. In addition, under hot conditions an $\mathrm{R}^{2} \geq 0.84$ (linear and

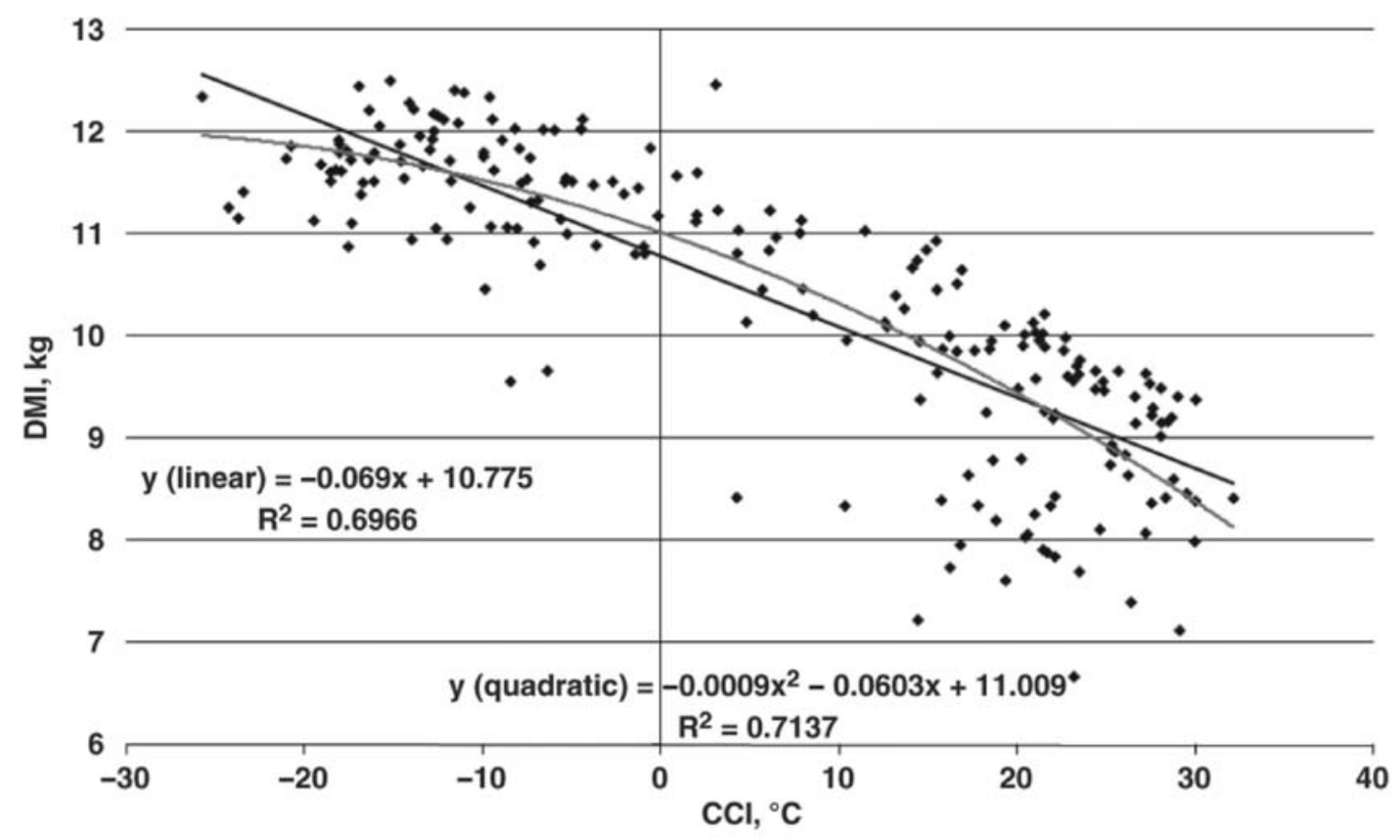

Figure 5. Relationship between comprehensive climate index (CCI) and DMI. 
quadratic) was found when comparing CCI with THI (graph not shown) and under cold conditions an $\mathrm{R}^{2} \geq 0.96$ (linear and quadratic) was found when comparing CCI with WCI (graph not shown).

The value of the index as an indicator of animal stress is shown in Table 2. Under summer conditions, the mean CCI value increased approximately 2 units each, when going from limited losses to up to $2 \%$ losses and when going from $2 \%$ losses to over $5 \%$ losses in livestock. The mean THI value increased when going from limited to up to $2 \%$ losses, but declined at the greater loss level. The adjusted THI was more definitive and followed the same trend as the CCI, whereas the HI followed the same trend as $\mathrm{CCI}$ with a smaller change in the HI noted when going from up to $2 \%$ to over $5 \%$ livestock losses. Another pertinent difference in these indices is that, based on maximum values, only the CCI and adjusted THI follow a trend indicating that conditions were deteriorating, an important indicator of the threat for potential stress. The maximum THI and $\mathrm{HI}$ values actually declined when going from the $2 \%$ loss to the over $5 \%$ loss locations. Under winter conditions, comparable mean, minimum, and maximum values were found between the $\mathrm{CCI}$ and the WCI, with the mean CCI values being slightly less than the $\mathrm{WCI}$ values.

As shown, the index is based on hourly environmental observations; index values for a wide range of environmental characteristics are shown in Table 3. For the characteristics provided, $\mathrm{CCI}$ values range from -44.1 $\left(\mathrm{Ta}=-30^{\circ} \mathrm{C}\right.$, WS $=9 \mathrm{~m} / \mathrm{s}, \mathrm{SR}=100 \mathrm{~W} / \mathrm{m}^{2}$, and $\left.\mathrm{RH}=80 \%\right)$ to $67.7(\mathrm{Ta}=$ $45^{\circ} \mathrm{C}, \mathrm{WS}=1 \mathrm{~m} / \mathrm{s}, \mathrm{SR}=900 \mathrm{~W} / \mathrm{m}^{2}$, and $\mathrm{RH}=80 \%$ ). Related CCI thresholds are shown in Table 4. Threshold definitions are considered arbitrary and are capable of being shifted based on many factors including age, adaptation effects, genetic composition, body insulation and fat content, size and shape (e.g., surface area exposure), and food and feed intake (Gaughan et al., 1999; Mader et al., 2002; Davis et al., 2003). Threshold levels were divided into apparent temperature increments of $5^{\circ} \mathrm{C}$. Heat stress ranged from 25 to $>45^{\circ} \mathrm{C}$, with threshold levels capable of being adjusted up and down. However, for cold stress, animal susceptibility varies more than under heat stress. Mammals, in particular, tend to have a greater capacity for coping with cold environmental conditions than with hot environmental conditions (Folk et al., 1998; Gaughan et al., 2009). Thus, the magnitude of the differences between threshold levels, as well as the point at which stress begins, will vary more under cold environmental conditions. Even though designated threshold levels, 


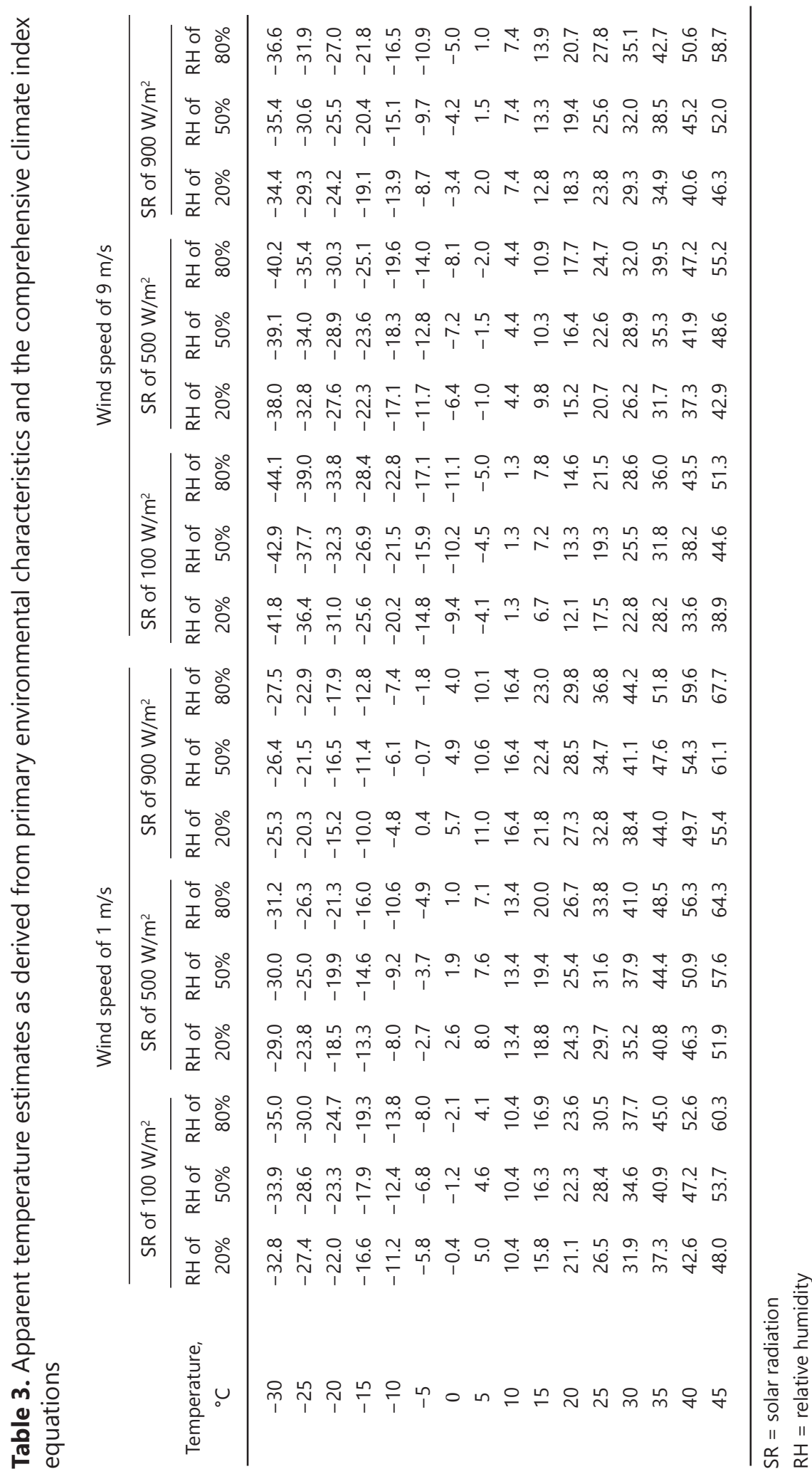


Table 4. Arbitrary comprehensive climate index thermal stress thresholds ${ }^{1}$

Hot conditions $^{2} \quad$ Cold conditions

\begin{tabular}{lccc} 
& & \multicolumn{2}{c}{ Animal susceptibility } \\
\cline { 3 - 4 } Environment & $<25$ & High & Low $^{4}$ \\
\hline No stress & 25 to 30 & $>5$ & $>0$ \\
Mild & $>30$ to 35 & $<0$ to 5 & 0 to -10 \\
Moderate & $>35$ to 40 & $<-5$ to -10 & $<-10$ to -20 \\
Severe & $>40$ to 45 & $<-10$ to -15 & $<-20$ to -30 \\
Extreme & $>45$ & $<-15$ & $<-30$ to -40 \\
Extreme danger & $>45$ & $<-40$ \\
\hline
\end{tabular}

1 Based on regression of the comprehensive climate index on the temperature-humidity index and the wind chill index. Threshold levels indicate intensity of climatic stress experienced by the animal.

2 Modified from indices developed by Mader et al. (2006), Gaughan et al. (2008), and the Livestock Weather Safety index (LCl, 1970) with severe thresholds capable of causing death of animals and extreme thresholds having a high probability of causing death of high-risk animals. For well-acclimated or heat-tolerant species, threshold values would shift down 1 or 2 categories (i.e., a crossbred Bos taurus $\times$ Bos indicus would most likely be in the mild category at $\mathrm{CCl}>30$ to 35 ).

3 Modified from NOAA, 2009. Generally, young or nonacclimated animals or both cared for under sheltered (housed) or modified environmental conditions.

4 Modified from Stanier et al. (1984) and Johnson (1994). Generally, unsheltered animals that have had adequate time to acclimate to outdoor environments through acquisition of additional external or tissue insulation or both and are receiving nutrient supplies compatible with the level of environmental exposure.

as shown in Table 4, are arbitrary, greater latitude is needed for defining threshold boundaries under cold conditions. Therefore, one set of thresholds was derived for animals that tend to be more susceptible to cold stress, and a separate set of thresholds were derived for animals that are less susceptible to cold stress. Nonacclimated animals that are housed in sheltered or managed environments certainly can begin to show signs of stress at $5^{\circ} \mathrm{C}$ and severe stress around $-5^{\circ} \mathrm{C}$, whereas animals managed in outside facilities and that have had opportunities to acclimate to cold may not display signs of severe stress until apparent temperature reaches $-20^{\circ} \mathrm{C}(\mathrm{NRC}, 1981)$. 


\section{Discussion}

Under most environmental conditions, temperature represents a major portion of the driving force for heat exchange between the environment and an animal (Hahn, 1999). However, moisture and heat content of the air, thermal radiation, and airflow also affect the total heat exchange (NRC, 1981; Mader and Davis, 2004; Mader et al., 2006). Thus, the effective or apparent temperature an animal responds to is a combination of environmental variables (Johnson, 1986; Fox and Tylutki, 1998).

Modifications to indices have been developed to overcome the shortcomings related to airflow and radiation heat loads. These indices account for effects of RH, WS, RAD, or all 3 under hot or cold environmental conditions, but not under both. Mader et al. (2006) developed adjustments to the THI for use with feedlot cattle, based on cattle panting scores and measures of WS and RAD. Eigenberg et al. (2005) developed a comparable index based on predictions of respiration rate using Ta, dew point temperature, WS, and RAD. Although the relative effects of WS and RAD varied between these equations, both indices account for the influence of hourly WS and RAD when heat stress mitigation strategies need to be implemented. Additionally, Gaughan et al. (2008) developed a more extensive index as a guide to the management of cattle during hot weather. The heat load index incorporates black globe (BG) temperature (Buffington et al., 1981), RH (decimal form), and WS. However, the index consists of 2 parts HLIBG $>25$ and $H L I B G<25$.

The above indices are for heat stress conditions only. Indices for cold stress are not as well-defined. The WCI has traditionally been used to derive an apparent temperature for humans. In 2001, the National Weather Service released a new WCI that has merit for use in determining effects of wind on humans as well as domestic livestock. The new index is a physiologically based model and accounts for inherent errors in the earlier WCI, which was not based on heat transfer properties of body tissues, although the old WCI did have some heat loss and equivalent temperature properties appropriate for sheep and cattle (Ames and Insley, 1975). These equations accounted for heat transfer through pelts and hides sections of previously slaughtered animals; however, they did not account for fat cover and other regulatory processes utilized in mitigating cold stress. In addition, body heat loss due to wind is proportional to the surface area exposed and not the entire surface area of the body. 
This error was inherent in the Ames and Insley (1975) equation and in the old WCI.

The WS component of the CCI was developed to depict the negative linear relationship between heat indices and WS as reported by Eigenberg et al. (2005) and Mader et al. (2006). However, Gaughan et al. (2008) found this relationship to be curvilinear. Thus, Eq. [2] is very close to linear until WS reach nearly $3 \mathrm{~m} / \mathrm{s}$, and then the effects of WS begin to diminish as found in the WCI and reported by Gaughan et al. (2008). The magnitude of the change in the HLI is less than the WCI per unit of WS. However, the shapes of the curves are similar and depicted in the CCI. Under cold conditions, Webster (1970) found a similar relationship and reported that external tissue insulation also displayed a curvilinear relationship with wind velocity. Because the response of the animal, primarily through heat loss, is curvilinear under hot and cold conditions, no additional adjustment was needed in the WS algorithm due to temperature.

The effects of RH under cold stress indicate that poor coat drying conditions are associated with livestock reared in outside conditions, which lose body heat due to hair coat and hide not staying dry under more humid conditions. Thus, an increase in RH results in a slight decrease in apparent temperature. An opposite effect is found under hot conditions with apparent temperature increasing with increasing humidity, due to the inability of the animal to transfer body heat. However, the CCI is not designed to predict apparent temperature for animals with wet hair coats. Nevertheless, the detrimental effects of wet, humid conditions at temperatures as low as $-15^{\circ} \mathrm{C}$ were clearly demonstrated by Wagner et al. (2008) in which, as a result of winter precipitation, winter $\mathrm{NE}_{\mathrm{m}}$ requirements were found to be 2.5 times greater than normal and 2.1 times greater than that predicted by the NRC (2000). Precipitation in the form of snow is quickly transformed to a liquid state, upon contact with the animal, even at Ta well below $0^{\circ} \mathrm{C}$. Excessive moisture contributes greatly to poor drying of the animal and increased maintenance energy requirements. Wet surface (ground and animal) conditions appear to sustain increased humidities, whereas dry surfaces allow moisture to migrate to them, and away from the animal, thus reducing $\mathrm{RH}$ and allowing for greater haircoat drying opportunities.

In livestock reared in outside facilities, pen/floor surfaces are radiation sources that act as heat emitters or heat sinks, and thus need to be 
accounted for in the index under cold and hot conditions (Mader et al., 2007). Equally important in areas of increased human traffic, soil and sealed surfaces radiate a significant amount of heat that does not get directly accounted for in many indices. However, vegetative or shaded surfaces have a temperature closer to Ta (Kelly et al., 1950; Buffington et al., 1981; Mader et al., 1999). The RAD component of heat stress indices has generally been found to be linear over a wide range of conditions (Eigenberg et al., 2005; Mader et al., 2006); Fox and Tylutki (1998) also reported linear effects between the hours of sunlight and effective temperature. However, the contribution of the DSR and STR component to the total radiation pool is evident and dependent on Ta and solar radiation levels. At temperature $<5^{\circ} \mathrm{C}$ surface correction will almost always be negative, especially when no solar radiation is present. With increasing solar radiation, the surface corrections become less negative to depict differences in day vs. night conditions. The effect of direct solar radiation component is always positive but increases per unit of radiation as well as with increasing Ta.

Environmental indices were also compared using weather data from north central North Dakota, and south central Arizona. The CCI was approximately 1 unit less (range $=1$ to -3 ) than the WCI under conditions in which both indices were between -40 and -50 . In Arizona, summer conditions where Ta can exceed $45^{\circ} \mathrm{C}$, the CCI was generally 3 to 7 units greater than the HI, due to the combination of slow $(<2 \mathrm{~m} / \mathrm{s}) \mathrm{WS}$ and increased ( $>900 \mathrm{~W}$ ) radiant heat loads, factors that are not taken into account with the HI.

For the summer conditions, all locations had maximum CCI that exceeded 40 . This has been determined to be a critical threshold, categorized as extreme, in which a high probability exists that livestock deaths can occur, particularly for animals being finished, unless mitigation strategies are implemented such as increasing water availability or providing shade or sprinkling. This threshold is also comparable with a THI of 84 and a $\mathrm{HI}$ of 37.8 (100 on $\mathrm{F}^{\circ}$ scale). The remaining CCI thresholds were designed to be aligned with similar thresholds utilized in other indices after appropriate transformation. It is important that thresholds be flexible because animal susceptibility to environmental factors differs. Primary factors influencing susceptibility include prior exposure, age, body condition, and insulation (NRC, 2000). Stanier et al. (1984) outlined 5 zones of cold stress, whereas Johnson (1994) outlined 3 cold 
stress thresholds, primarily for use with mature beef and dairy animals. The 5 thresholds described in NOAA (2009) were designed for newborn livestock and best fit nonacclimated or housed animals (or both) that may be particularly susceptible to cold stress.

The CCI was found to be very definitive with livestock losses being reported in all locations under the extreme threshold category. But even within this stress category, the CCI was able to distinguish and separate stress based on climatic conditions, where most other indices failed to do so. This is most clearly shown by the daily maximum CCI, which were obtained during the heat events. Within the extreme stress category, the percentages of cattle loss (degree of stress) were ranked in exactly the same order as the maximum CCI obtained. In cold stress situations, the CCI makes slight adjustments for RH but more importantly adjusts Ta for RAD (or the lack of), an important component of assessing animal comfort in an outside environment.

The bottom end (mild) of the heat stress categories was established at a CCI of 25. This was a value that was found to be prevalent during morning conditions for all heat events and would be evident under conditions in which no or limited nighttime cooling occurred. Also, for mature domestic livestock, including cattle, sheep, swine, and poultry, declines in feed intake or productivity or both occur at temperatures between 23 and $27^{\circ} \mathrm{C}$ or around $25^{\circ} \mathrm{C}$ (NRC, 1981). However, for high-producing animals fed high-energy diets, the lower threshold for heat stress may be closer to $20^{\circ} \mathrm{C}$ than $25^{\circ} \mathrm{C}$ (Brown-Brandl et al., 2006), which equates to comparable CCI values. Furthermore, all domestic livestock display significant reductions in $\mathrm{DMI}$ or have no feed intake at $40^{\circ} \mathrm{C}$, which would also be the case for CCI of 40 . Also, at $5^{\circ} \mathrm{C}$, most species display moderate to significant increases in DMI due to mild or moderate cold stress. However, cold stress thresholds may be more variable depending on factors discussed previously. For some animals, especially very young and newborn, mild cold stress could be experienced at apparent temperatures above $5^{\circ} \mathrm{C}$. Thus, shifting the mild thresholds to 10 or possibly $15^{\circ} \mathrm{C}$ apparent temperature may be appropriate for those animals.

Aside from the benefits of obtaining an apparent temperature for assessing comfort level, the continuous range of temperature in which the CCI can be utilized would be useful for calculating projected potential effects of climate change. In addition, net energy requirements could be determined based on a continuous range of conditions, 
thereby allowing a better definition of thermal comfort and thermoneutral zones. Physiological and metabolic responses to the environment are a result of a combination of environmental factors. Animal health, performance, and general behavior can be affected by these factors. A multi-factor index would be far superior to a single factor index for determining environmental effects on animal well-being. The CCI in effect would provide a better estimate of environmentally related energy expenditures that are not based solely on Ta. Currently, the NRC (2000) adjustment for DMI and $\mathrm{NE}_{\mathrm{m}}$ for Ta are previously defined from equations found in the NRC (1981) with external insulation adjustments for wind only. In addition, Johnson (1986) determined adjustments for DMI and $\mathrm{NE}_{\mathrm{m}}$ based on effective Ta as determined by the WCI (Bourdon et al., 1984). Based on that analysis, the WCI does have merit in assessing environmental effects on animals; however, appropriate adjustments for $\mathrm{RH}$ and RAD would be useful. The CCI is able to combine the effects of Ta, RH, WS, and RAD into one index, which has potential for use in assessing environmental effects on animal health, comfort, welfare, maintenance, and productivity.

\section{Conclusions}

For strategic decision-making, the goal should be to have an index that is broadly applicable across life stages and species, to maximize the utility of probability information (Hahn et al., 2003). Indices are needed that are comprehensive in nature and allow for greater application across a range of conditions. The CCI provides an adjustment to Ta for RH, WS, and RAD under hot and cold conditions. Apparent temperature can be adjusted up or down as these environmental conditions change. Additionally, the CCI incorporates effects of surface conditions that affect heat exchange between an animal and the environment. This index will be useful for further development of biological response functions, which are associated with energy exchange, and improving decision-making processes that are weather- dependent. In addition, the defined thresholds can serve as management and environmental mitigation guidelines to protect and ensure animal comfort. 


\section{Literature cited}

Ames, D. R., and L. W. Insley. 1975. Wind-chill effect for cattle and sheep. J. Anim. Sci. 40:161-165.

Amundson, J. L., T. L. Mader, R. J. Rasby, and Q. S. Hu. 2006. Environmental effects on pregnancy rate in beef cattle. J. Anim. Sci. 84:3415-3420.

Anderson, V., and J. Schoonmaker. 2005. Effects of bedding material on performance and carcass traits of steers fed during the winter in North Dakota. NDSU Beef Feedlot Res. Rep. North Dakota State Univ. 28:7-11.

Anderson, V. L., R. J. Wiederholt, and J. P. Schoonmaker. 2006. Effects of bedding feedlot cattle during the winter on performance, carcass quality, and nutrients in manure. NDSU Beef Feedlot Res. Rep. North Dakota State Univ. 29:28-36.

Arias, R. A. 2008. Modeling the effects of environmental factors on finished cattle. PhD Diss. Univ. Nebraska, Lincoln.

Arias, R. A., and T. L. Mader. 2009. Effects of surface soil temperature on daily water intake in feedlot cattle. Pages 105-106 in Nebraska Beef Report MP92. Univ. Nebraska, Lincoln.

Birkelo, C. P., and J. Lounsbery. 1992. Effect of straw and newspaper bedding on cold season feedlot performance in two housing systems. Pages 42-45 in SDSU Beef Report. South Dakota State Univ., Brookings.

Bond, T. E., C. F. Kelly, S. R. Morrison, and N. Pereira. 1967. Solar, atmospheric and terrestrial radiation received by shaded and unshaded animals. Trans. Am. Soc. Agric. Eng. 10:662-627.

Bourdon, R. M., D. E. Johnson, and D. R. Ames. 1984. Simulated effects of cold stress on maintenance requirements of beef cattle. Beef Program Rep. Special series 32, Colorado State Univ., Fort Collins.

Brown-Brandl, T. M., R. A. Eigenberg, and J. A. Nienaber. 2006. Heat stress factors of feedlot heifers. Livest. Sci. 105:57-68.

Brown-Brandl, T. M., J. A. Nienaber, G. L. Hahn, and R. A. Eigenberg. 2008. Analysis of meteorological parameters of different extreme heat waves. Pages 849-855 in Symp. Proc.: Livest. Environment VII Proc. 8th Int. Symp., Iguassu Falls, Brazil. Aug. 31-Sep. 4, 2008.

Buffington, D. E., A. Colazon-Arocho, G. H. Canton, and D. Pitt. 1981. Black globehumidity index (BGHI) as comfort equation for dairy cows. Trans. Am. Soc. Agric. Eng. 24:711-714.

Cattle Network. 2009. Nearly 4,000 Nebraska cattle die in heat wave. https:// www.cattlenetwork.com/Nearly-4,000-Nebraska-Cattle-Die-In-HeatWave/2009-07-07/Article.aspx?oid=487812\&tid=Archive Accessed Sep. 17, 2009.

Davis, M. S., T. L. Mader, S. M. Holt, and A. M. Parkhurst. 2003. Strategies to reduce feedlot cattle heat stress: Effects on tympanic temperature. J. Anim. Sci. 81:649-661.

Eigenberg, R. A., T. M. Brown-Brandl, J. A. Nienaber, and G. L. Hahn. 2005. Dynamic response indicators of heat stress in shaded and non-shaded feedlot cattle. Part 2: Predictive relationships. Biosystems Eng. 91:111-118. 
Folk, G. E., M. L. Reidesel, and D. L. Thrift. 1998. Principles of integrative environmental physiology. Austin \& Winfield, San Francisco, CA.

Fox, D. G., and T. P. Tylutki. 1998. Accounting for the effects of environment on the nutrient requirements of dairy cattle. J. Dairy Sci. 8:3085-3095.

Gaughan, J., N. Lacetera, S. E. Valtorta, H. H. Khalifa, L. Hahn, and T. Mader. 2009. Response of domestic animals to animal challenges. Chapter 7 in Biometeorology for Adaptation to Climate Variability and Change. K. L. Ebi, I. Burton, and G. R. McGregor, ed. Springer, the Netherlands.

Gaughan, J. B., T. L. Mader, S. M. Holt, M. J. Jose, and K. J. Rowan. 1999. Heat tolerance of Boran and Tuli crossbred steers. J. Anim. Sci. 77:2398-2405.

Gaughan, J. B., T. L. Mader, S. M. Holt, and A. Lisle. 2008. A new heat load index for feedlot cattle. J. Anim. Sci. 86:226-234.

Hahn, G. L. 1999. Dynamic responses of cattle to thermal heat loads. J. Anim. Sci. 77(Suppl. 2):10-20.

Hahn, G. L., T. L. Mader, and R. A. Eigenberg. 2003. Perspective on development of thermal indices for animal studies and management. Pages 31-45 in Symp. Proc.: Interactions Between Climate and Animal Production. EAAP Technical Series No. 7. Wageningen Academic Publ., Wageningen, the Netherlands.

Hubbard, K. G., N. J. Rosenberg, and D. C. Nielsen. 1983. Automated weather data network for agriculture. J. Water Resour. Plan Manage. 109:213-222.

Johnson, D. E. 1986. Climatic stress and production efficiency. In Limiting the Effects of Stress on Cattle. G. P. Moberg, ed. West. Reg. Res. Publ. No. 009 and Utah Agricultural Experiment Station Utah State University, Logan, Utah Res. Bull. 512. Dec. 1986.

Johnson, H. D. 1994. Animal Physiology. Pages 44-58 in Handbook of Agricultural Meteorology. J. F. Griffiths, ed. Oxford Univ. Press, New York, NY.

Kelly, C. F., and T. E. Bond. 1971. Bioclimatic factors and their measurement. Pages 7-92 in A Guide to Environmental Research on Animals. Natl. Acad. Sci., Washington, DC.

Kelly, C. F., T. E. Bond, and N. R. Ittner. 1950. Thermal design of livestock shades. Agric. Eng. 30:601-606.

Keren, E. N., and B. E. Olson. 2006. Thermal balance of cattle grazing winter range: Model application. J. Anim. Sci. 84:1238- 1247.

Kreikemeier, W. M., and T. L. Mader. 2004. Effects of growth-promoting agents and season on yearling feedlot heifer performance. J. Anim. Sci. 82:2481-2488.

LCI. 1970. Patterns of transient losses. Livest. Conserv. Inc., Omaha, NE.

Mader, T. L. 2003. Environmental stress in confined beef cattle. J. Anim. Sci. 81(E. Suppl. 2):110-119.

Mader, T. L., and S. L. Colgan. 2007. Pen density and straw bedding during feedlot finishing. Pages 43-46 in Nebraska Beef Rep. MP90. Univ. Nebraska, Lincoln.

Mader, T. L., J. M. Dahlquist, and J. B. Gaughan. 1997. Wind Protection effects and airflow patterns in outside feedlots. J. Anim. Sci. 75:26-36. 
Mader, T. L., J. M. Dahlquist, G. L. Hahn, and J. B. Gaughan. 1999. Shade and wind barrier effects on summer-time feedlot cattle performance. J. Anim. Sci. 77:2065-2072.

Mader, T. L., and M. S. Davis. 2004. Effect of management strategies on reducing heat stress of feedlot cattle: Feed and water intake. J. Anim. Sci. 82:3077-3087.

Mader, T. L., M. S. Davis, and T. Brown-Brandl. 2006. Environmental factors influencing heat stress in feedlot cattle. J. Anim. Sci. 84:712-719.

Mader, T. L., M. S. Davis, and J. B. Gaughan. 2007. Effect of sprinkling on feedlot microclimate and cattle behavior. Int. J. Biomet. 51:541-551.

Mader, T. L., S. M. Holt, G. L. Hahn, M. S. Davis, and D. E. Spiers. 2002. Feeding strategies for managing heat load in feedlot cattle. J. Anim. Sci. 80:2373-2382.

Nienaber, J. A., and G. L. Hahn. 2007. Livestock production system management responses to thermal challenges. Int. J. Biometeorol. 52:149-157.

NOAA. 2009. How CANL works. http://www.wrh.noaa.gov/ggw/canl/works.html Accessed Aug. 27, 2009.

NRC. 1981. Effect of Environment on Nutrient Requirements of Domestic Animals. Natl. Acad. Press, Washington, DC.

NRC. 2000. Nutrient Requirements of Beef Cattle. 7th ed. Natl. Acad. Press, Washington, DC.

Rothfusz, L. P. 1990. Heat Index "Equation" (or, more than you ever wanted to know about heat index). NWS Technical Attachment SR 90-23. National Weather Service. http://www.srh.noaa.gov/images/ffc/pdf/ta_htindx.PDF Accessed Mar. 15, 2010.

Siple, P. A., and C. F. Passel. 1945. Measurements of dry atmospheric cooling in subfreezing temperatures. Proc. Am. Philos. Soc. 89:177-199.

Stanier, M. W., L. E. Mount, and J. Bligh. 1984. Energy balance and temperature regulation. Cambridge Univ. Press, Cambridge, UK.

Stanton, T. L., and D. N. Schutz. 1996. Effect of bedding on finishing cattle performance and carcass characteristics. Beef Program Rep. Colorado State Univ. 37-41.

Tew, M., G. Battel, and C. A. Nelson. 2002. Implementation of a new Wind Chill Temperature Index by the National Weather Service. 18th Int. Conf. Interactive Information and Processing Systems (IIPS) for Meteorology, Oceanography, and Hydrology, Orlando, FL. Am. Meteor. Soc. 203-205.

Thom, E. C. 1959. The discomfort index. Weatherwise 12:57-59.

Wagner, J. J., P. T. Grubb, and T. E. Engle. 2008. Case study: The effects of severe winter weather on net energy for maintenance required by yearling steers. Prof. Anim. Sci. 24:494-499.

Webster, A. J. F. 1970. Direct effects of cold weather on the energetic efficiency of beef production in different regions of Canada. Can. J. Anim. Sci. 50:563-573. 